\title{
Prevalence, severity and risk factors of allergic disorders among people in south India.
}

\author{
Nitin Joseph ${ }^{1}$, Revathi Palagani ${ }^{1}$, Shradha $\mathrm{NH}^{1}$, Vaibhav Jain ${ }^{1}$, \\ Kowshik K ${ }^{1}$, Roshan Manoharan ${ }^{1}$, Maria Nelliyanil ${ }^{2}$
}

1. Kasturba Medical College, Manipal University, Mangalore, Community Medicine.

2. A.J Institute of Medical Sciences, Community Medicine.

\begin{abstract}
Background: Allergic disorders are not usually life-threatening conditions but they impair the person's ability to function. It thus adversely affects the psychological wellbeing and quality of life. These implications of allergic disorders can be minimized if strategies are planned for its early identification followed by appropriate interventions.

Objectives: To find out the prevalence and risk factors of allergic disorders.

Methods: Data was collected by house to house survey among participants aged 18 years and above using a standardized allergy assessment questionnaire.

Results: Mean age of the 400 participants was $42.8 \pm 14.7$ years. Majority 105(26.2\%) were in the age group 36 to 45 years. Majority were females 287(71.7\%) and were house wives 217(54.2\%). Majority of participants were of upper socio economic class $98(44.7 \%)$ out of 219 and majority were from urban areas 326(81.5\%). The prevalence of allergy among participants was found to be $115(28.7 \%)$. Out of these $115,37(32.2 \%)$ had possibility of allergy, $60(52.2 \%)$ had probability of allergy and the rest 18(15.6\%) had very high likelihood for allergy. People residing in semi urban areas had increased risk of allergy $(p=0.024)$ than those from urban areas. The prevalence of asthma was 30(7.5\%) and skin allergy was $23(5.8 \%)$. Most common precipitating factors for allergy were dust exposure 103(25.8\%) followed by seasonal changes $71(17.8 \%)$. Family history of allergy was associated with allergy among participants $(\mathrm{p}<0.001)$. Usage of firewood was associated with symptoms of respiratory allergy among participants $(\mathrm{p}=0.01)$.

Conclusion: The study revealed some important determinants of allergic disorders which have important implications to frame appropriate prevention and health educational strategies.

Keywords: Allergy, prevalence, risk factors, semi-urban areas, urban areas.

DOI: http://dx.doi.org/10.4314/ahs.v16i1.27

Cite as: Joseph N, Palagani R, Shradha NH, Jain V, Kowshik, K, Manoharan R, Nelliyanil M. Prevalence, severity and risk factors of allergic disorders among people in south India. Afri Health Sci. 2016;16(1): 201- 209. bttp:// dx.doi.org/10.4314/abs.v16i1.27
\end{abstract}

\section{Introduction}

An allergic condition is a hypersensitivity disorder in which the immune system reacts to substances in the environment that are normally considered harmless. These chronic diseases are common worldwide with high prevalence reported in all age groups. ${ }^{1}$ Incidence and prevalence of allergic disorders has increased considerably in recent decades. ${ }^{2-4}$ Allergic disorders are believed to result from a complex interplay between genetic and environmental factors. ${ }^{4,5}$ Unfortunately there is a paucity of information and dearth of epidemiological data about allergic disorders in India. ${ }^{6}$

\footnotetext{
Corresponding author:

Nitin Joseph,

Kasturba Medical College,

Manipal University, Mangalore,

Community Medicine.

Email:drnitinjoseph@gmail.com
}

Allergic disorders like asthma are often under-diagnosed and undertreated, creating considerable burden on individuals and families ${ }^{7}$ It is responsible for approximately $1 \%$ of all disability-adjusted life years lost worldwide. ${ }^{7}$ Allergic disorders and its complications has also been reported to increase health care costs of the individual. ${ }^{8}$ Therefore even though mostly a non-life threatening condition, they can impair the person's ability to function. It thus has a huge socioeconomic impact and can adversely influence psychological wellbeing and quality of life. ${ }^{4,9,10}$

Presence of one allergic disorder has been found to increase the risk of other allergic disorders affecting different organ systems. ${ }^{11,12}$ These implications of allergic disorders can be minimized if strategies are planned for its early identification followed by appropriate interventions.

Therefore this study was aimed to find out the prevalence of allergy among people and to explore its re- 
lationship with risk factors. The results of this study would form a baseline for epidemiological surveillance of allergic disorders. This would help further to design and implement primary health care measures to prevent further disease burden. The diverse demographic, cultural and social conditions observed in South Canara district of Karnataka state in south India would be an ideal setting to explore the risk factors of allergy.

\section{Materials and methods}

This cross-sectional study was done in April 2014 in field practice areas of Department of Community Medicine of this private medical college. This comprised of urban areas namely Jeppinamogaru, Boloor, Lady Hill and a semi-urban area namely Shivanagar. The approval for conducting this study was obtained from Institutional Ethic Committee of Kasturba Medical College, Mangalore.

The minimum sample size of 243 participants was calculated at $95 \%$ confidence limits, $85 \%$ power and prevalence of allergic disorders in the community assumed to be $42.3 \%$ based on the findings of a previous survey. ${ }^{13}$ However a total of 400 participants could be enrolled during the study period. These participants were chosen from households by systematic random sampling method. Here every 10th house starting from the first house chosen by simple random sampling technique were surveyed. In case the house was locked the next adjacent house was selected.

Any person aged $\geq 18$ years, literate and consenting to participate per house was enrolled in this study. Written informed consent was obtained from each participant after explaining to them the nature and purpose of the study using an information sheet printed in local language, Kannada. The data was collected by interviewing each participant using a standardized allergy assessment questionnaire ${ }^{14}$ translated into Kannada. The questionnaire was language validated by translation and back translation with the help of language experts. Pre testing of the tool was done among ten non randomly chosen participants who were not part of the main study. The questionnaire consisted of fifteen questions to assess allergic disorders. Participants were asked about presence or absence of these symptoms over the past one month. The questions had differential weighted scores allotted by the manufacturers and cumulative scores in the range below 8 were categorized as allergy unlikely, 8 to 12 as allergy possible, 13 to 20 as allergy probable and more than 20 as allergy very likely. Socio economic status was assessed using Modified BG Prasad Classification of 2014. Data was entered and analyzed using SPSS Inc., Chicago, IL version 11.0. Chi-square was used to test the association of various socio demographic variables with risk of developing allergy among participants. $\mathrm{p}$ value $\leq 0.05$ was taken as significant association.

\section{Results}

Mean age of the 400 participants were $42.8 \pm 14.7$ years. Majority $105(26.2 \%)$ were in the age group 36 to 45 years. Majority were females $287(71.7 \%$ ) and were house wives $217(54.2 \%)$. Majority of participants were of upper socio economic class, 98(44.7\%) out of 219 and majority were from urban areas 326(81.5\%). The prevalence of allergy among participants was found to be $115(28.7 \%)$. Out of these $115,37(32.2 \%)$ had possibility of allergy, $60(52.2 \%)$ had probability of allergy and the rest $18(15.6 \%)$ had very high likelihood for allergy (Table 1).

Allergy was seen among greater proportion of people residing in semi-urban areas $(\mathrm{p}=0.024)$ compared to urban areas. No other socio demographic variables were associated with risk of developing allergy among participants. (Table 1) 
Table 1: Association between socio demographic variables with risk of allergy among participants.

\begin{tabular}{|c|c|c|c|c|c|}
\hline Characteristics & Allergy unlikely (\%) & Allergy possible (\%) & Allergy probable (\%) & Allergy very likely (\%) & Total \\
\hline \multicolumn{6}{|l|}{ Age (years) } \\
\hline $18-25$ & $37(62.7)$ & $4(6.8)$ & $13(22)$ & $5(8.5)$ & 59 \\
\hline $26-35$ & $59(74.7)$ & $9(11.4)$ & $9(11.4)$ & $2(2.5)$ & 79 \\
\hline $36-45$ & $77(73.3)$ & $10(9.5)$ & 18(17.1) & $0(0)$ & 105 \\
\hline $46-55$ & $45(66.2)$ & $9(13.2)$ & $8(11.8)$ & $6(8.8)$ & 68 \\
\hline $56-65$ & $38(70.4)$ & $3(5.6)$ & $10(18.5)$ & $3(5.6)$ & 54 \\
\hline \multirow[t]{2}{*}{65 and above } & 29(82.9) & $2(5.7)$ & $2(5.7)$ & $2(5.7)$ & 35 \\
\hline & & & & \multicolumn{2}{|l|}{$X^{2}=21.3, p=0.125$} \\
\hline \multicolumn{6}{|l|}{ Gender } \\
\hline Males & $88(77.9)$ & $8(7.1)$ & $13(11.5)$ & $4(3.5)$ & 113 \\
\hline \multirow[t]{2}{*}{ Females } & 197(68.6) & $29(10.1)$ & $47(16.4)$ & $14(4.9)$ & 287 \\
\hline & & & & \multicolumn{2}{|l|}{$X^{2}=3.378, p=0.337$} \\
\hline \multicolumn{6}{|l|}{ SES $(n=219)$} \\
\hline Upper class & $79(80.6)$ & $5(5.1)$ & 13(13.3) & 1(1) & 98 \\
\hline Upper middle & $55(67.1)$ & $8(9.8)$ & $15(18.3)$ & $4(4.9)$ & 82 \\
\hline \multirow[t]{2}{*}{ Middle/ Lower middle/ Lower } & $27(69.2)$ & $6(15.4)$ & $4(10.3)$ & $2(5.1)$ & 39 \\
\hline & & & & \multicolumn{2}{|l|}{$\mathrm{X}^{2}=8.829, \mathrm{p}=0.183$} \\
\hline \multicolumn{6}{|l|}{ Occupation } \\
\hline Professional & $45(79)$ & $3(5.2)$ & $7(12.3)$ & $2(3.5)$ & 57 \\
\hline Semi-professional & $5(41.7)$ & $3(25)$ & $3(25)$ & $1(8.3)$ & 12 \\
\hline Businessman & $34(79.1)$ & $4(9.3)$ & $3(7)$ & $2(4.6)$ & 43 \\
\hline Unskilled workers & $26(70.3)$ & $3(8.1)$ & $7(18.9)$ & $1(2.7)$ & 37 \\
\hline Housewives & $153(70.5)$ & $23(10.6)$ & $33(15.2)$ & $8(3.7)$ & 217 \\
\hline \multirow[t]{2}{*}{ Students } & $22(64.7)$ & $1(2.9)$ & $7(20.6)$ & $4(11.8)$ & 34 \\
\hline & & & & \multicolumn{2}{|l|}{$X^{2}=17.8, p=0.274$} \\
\hline \multicolumn{6}{|l|}{ Place } \\
\hline Urban & 239(73.3) & $29(8.9)$ & $48(14.7)$ & $10(3.1)$ & 326 \\
\hline \multirow[t]{2}{*}{ Semi-urban } & $46(62.2)$ & $8(10.8)$ & $12(16.2)$ & $8(10.8)$ & 74 \\
\hline & & & & \multicolumn{2}{|l|}{$X^{2}=9.4, p=0.024$} \\
\hline Total & 285 & 37 & 60 & 18 & 400 \\
\hline
\end{tabular}

The prevalence of asthma was 30(7.5\%) and skin aller- dust exposure 103(25.8\%) followed by seasonal changgy was $23(5.8 \%)$. (Table 2 ) es $71(17.8 \%)$. Allergy to food substances was reported Most common precipitating factors for allergy were by $16(4 \%)$ participants. 
Table 2: Prevalence of allergic symptoms among participants $(n=400)$.

\begin{tabular}{|c|c|c|}
\hline Allergic symptoms & Number & Percentage \\
\hline Sinus problems, frequent cold, head ache & 83 & 20.8 \\
\hline Recurrent sneezing, nasal discharge & 66 & 16.5 \\
\hline Nasal congestion, post nasal drip & 50 & 12.5 \\
\hline Itching, watering, redness, swelling of eyes & 50 & 12.5 \\
\hline Asthma, tight chest, chronic cough & 30 & 7.5 \\
\hline Skin problems like eczema, dermatitis, itching & 23 & 5.8 \\
\hline $\begin{array}{l}\text { Gastro intestinal symptoms like recurrent } \\
\text { indigestion, bloating, diarrhea, constipation }\end{array}$ & 22 & 5.5 \\
\hline Chronic fatigue, tiredness & 48 & 12.0 \\
\hline
\end{tabular}

This comprised of 10 for sea foods, 5 for vegetables drugs were antibiotics namely, penicillin in one case, like cucumber and lady finger and one towards peanuts. ciprofloxacin in two cases and sulfa drugs in three out Four people gave history for drug allergy. All these of four cases. (Table 3)

Table 3: Precipitating factors for allergy among participants $(n=400)$.

\begin{tabular}{|c|c|c|}
\hline Precipitating factors & Number & Percentage \\
\hline Seasonal change & 71 & 17.8 \\
\hline Going outdoors & 42 & 10.5 \\
\hline Visiting parks or grassy areas & 24 & 6.0 \\
\hline Dust exposure & 103 & 25.8 \\
\hline Contact with animals & 11 & 2.8 \\
\hline Worsening of symptoms after awakening or in the morning & 39 & 9.8 \\
\hline Food substances & 16 & 4.0 \\
\hline Medications & 4 & 1.0 \\
\hline
\end{tabular}


Family history of allergy was associated with allergy pants, 362(90.5\%) consumed mixed diet and 15(3.7\%) among participants $(\mathrm{p}<0.001)$. Of the total partici- were smokers. (Table 4)

Table 4: Association of other risk factors like smoking, diet, type of cooking fuel used at home and family history of allergy with risk of allergy among participants

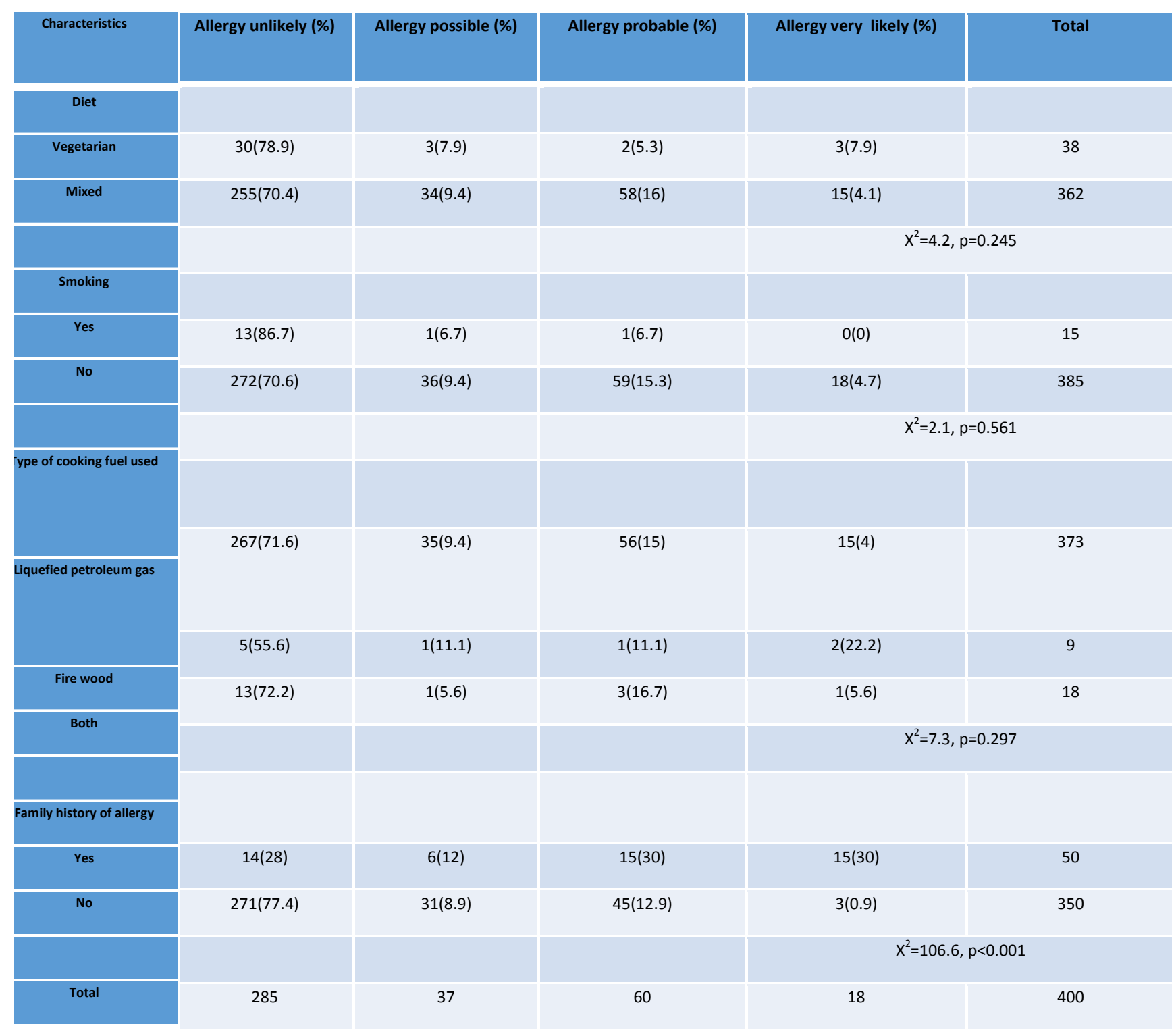

Usage of firewood was associated with symptoms of respiratory allergy among participants $(\mathrm{p}=0.01)$. (Table 5) Gastro intestinal (GI) symptoms like recurrent indi- gestion, bloating, diarrhoea and constipation was seen among 20(5.5\%) participants who were non vegetarians compared to $2(5.3 \%)$ who were vegetarians $\left(\mathrm{X}^{2}=0.005\right.$, $\mathrm{p}=0.946)$. 


\begin{tabular}{|c|c|c|c|}
\hline Characteristics & \multicolumn{2}{|c|}{ Respiratory allergy } & \multirow[t]{2}{*}{ Total } \\
\hline Smoking & Symptoms present & Symptoms absent & \\
\hline Yes & $0(0)$ & $15(100)$ & 15 \\
\hline \multirow[t]{2}{*}{ No } & $30(7.8)$ & $355(92.2)$ & 385 \\
\hline & & & $X^{2}=1.3, p=0.261$ \\
\hline \multicolumn{4}{|l|}{ Cooking fuel } \\
\hline Liquefied petroleum gas & $23(6.2)$ & $350(93.8)$ & 373 \\
\hline Firewood & $2(22.2)$ & $7(77.8)$ & 9 \\
\hline \multirow[t]{2}{*}{ Both } & $5(27.8)$ & $13(72.2)$ & 18 \\
\hline & & & $X^{2}=14.4, p=0.01$ \\
\hline Total & 30 & 370 & 400 \\
\hline
\end{tabular}

\section{Discussion}

The prevalence of allergy was $28.7 \%$ in this study compared to $42.3 \%$ self-reported by participants in another community based study done by Enroth $\mathrm{S}$ et al. ${ }^{13}$ Prevalence of rhinitis was reported to be ranging from $11.3 \%$ to $61.9 \%$ in previous Asian studies ${ }^{12,15-17}$ and $22.5 \%$ in a European study ${ }^{9}$ and $32 \%$ in a study done in Colombia $^{18}$ compared to $16.5 \%$ reported in this study. Allergic rhinitis has been found to adversely influence quality of patients by affecting mood, work, social functioning and sleep. It has also been found to increase medical expenditure and increase indirect cost due to absenteeism and loss of productivity. ${ }^{19}$

Itching and watering of the eyes was reported by $4 \%$ in a study done in Netherlands ${ }^{20}$ and by $20 \%$ in a study done in Colombia ${ }^{18}$ compared to $12.5 \%$ in this study. The prevalence of asthma in other studies ranged from $2.8 \%$ to $26.7 \% .^{12,13,15-18}$ compared to $7.5 \%$ observed in this study.

The prevalence of skin allergy was $5.8 \%$ in the present study compared to other studies where it ranged from $1.2 \%$ to $14 \%{ }^{3,12,13,18,20}$ In a study done in Netherlands GI symptoms like stomach cramps, vomiting, and diarrhea as a consequence of allergy was reported by $15 \%$ compared to $5.5 \%$ participants in this study. ${ }^{20}$

Seasonal change was responsible for allergy among $17.8 \%$ people in the present study. Similarly a study done in Taiwan reported that environmental factors like temperature and humidity exacerbate allergy. ${ }^{12}$ In an- 
other study done in Bolivia, outdoor air pollutants were responsible for asthma and allergies. ${ }^{21}$ This supports the role of environmental factors involved in occurrence of allergic disorders.

Allergy prevalence in a Swedish study was inversely correlated with number of hours spent outdoors. ${ }^{13}$ On the contrary in this study, going outdoors precipitated allergy in $10.5 \%$ cases.

In this study exposure to dust precipitated allergy in $25.8 \%$ participants. A record based study done in Iran reported that house dust mites were the predominant sensitizing allergens in $89.7 \%$ patients. $^{2}$ Visiting parks or grassy areas has been found to precipitate allergy in $6 \%$ of cases in this study. This again supports the role of pollens as the major source of allergens responsible for 10 to $20 \%$ of allergic diseases in the community, the most common of which being rhinitis. ${ }^{2}$

In this study contact with animals was found to precipitate allergic symptoms in $2.8 \%$ individuals. In a study done in Bolivia, presence of farm animals were statistically significant predictors of allergic disorders like asthma symptoms, rhino conjunctivitis and eczema. ${ }^{21}$ The Isaac III study in Bogota also observed that symptoms of asthma was correlated with the presence of animals at home. ${ }^{22}$ Therefore removal of the pets from the home is recommended for sensitized patients with allergic diseases. ${ }^{5}$

In this study, 4\% participants reported food allergy in comparison to findings of other studies where it ranged from $2 \%$ to $24.9 \%{ }^{6,13,23,24}$ Individuals with food allergy have reported social isolation, depression and poor quality of life. ${ }^{25}$ This could be due to anxiety associated with being continuously alert to their eating habits due to fear of allergic reactions. ${ }^{20}$ Severe food allergy adversely influences the diet and lifestyle of individuals thus posing socio-economic burden on their families. In this study sea foods were the most common food item reported to cause allergy. In other studies the most common allergenic foods where milk, eggs, peanuts and fish. ${ }^{6,13,20,23}$ Genetic factors are known to be incriminated with allergic reactions to food. ${ }^{26}$ Such individuals should take plenty of fruits and vegetables which are rich in antioxidants, hence beneficial in preventing allergic diseases. ${ }^{27,28}$

In a Swedish study, allergy prevalence was inversely correlated with age in contrast to our observations where no association was noticed. ${ }^{13}$ In this study females had slightly increased risk of allergic disorders while a study done in Taiwan found allergic disorders to be significantly more among females. ${ }^{12}$ The risk of developing allergy was significantly associated with family history of the same in this study and several other studies. ${ }^{2,29-31}$ Studies have also observed that this increased risk seemed to be present no matter whichever type of allergic diseases were in family members indicating strong genetic component irrespective of varying prevalence and environmental risk factors of allergies in different societies. ${ }^{4,32}$ These genetic factors form the non-modifiable factors in causation of allergies which cannot be controlled.

In a study done in Korea, people from higher socio economic status were found to significantly suffer from allergic disorders like atopic dermatitis which was different from our observations where no association was seen. ${ }^{3}$ In this study allergic disorders were significantly more in semi urban areas compared to urban areas which was different from other studies where it was significantly more in urban areas.,

In this study use of fire wood was associated with respiratory allergy. Similarly in other studies, adjusted models showed that exposure to wood or coal as cooking fuel were associated with an increase in asthma symptoms over domestic gas appliances. ${ }^{21,33}$ However no association of smoking with respiratory or other allergic symptoms was observed here similar to the findings of a study done in Japan where no association between cigarette smoking and atopic eczema was reported. ${ }^{34} \mathrm{~A}$ case-control study in Taiwan on the other hand found that adult-onset atopic eczema was seen in greater proportion of smokers. ${ }^{35}$

From the observations in this study we conclude that allergic disorders are very common affecting about one in three adults in this settings. Respiratory symptoms were the most common manifestation and was significantly associated with use of firewood. Family history of allergy was significantly associated with presence of allergy among participants.

People in semi urban areas were significantly more affected than people residing in urban areas. Other common risk factors for allergy reported were dust exposure and seasonal changes. The study revealed some important determinants of allergic disorders which might have important implications for development of suitable health education measures and to plan appropriate prevention strategies. Moreover a multidisciplinary team approach consisting of pulmonologist, dermatol- 
ogist, nurses, dietitians and health care workers would be ideal to control allergic disorders in the settings.

\section{Limitations}

The diagnosis of allergy was based on self-reported symptoms and not by laboratory investigations. Also further research is needed to identify the role of genetic factors in causation of allergy.

\section{Acknowledgements}

The authors of this study would like to thank all the participants for their enthusiasm and cooperation for taking part in this study.

\section{Source of support: \\ Nil}

\section{Conflict of interest:}

None declared

\section{References}

1. Mallol J, Crane J, von Mutius E, Odhiambo J, Keil U, Stewart A, et al. The International Study of Asthma and Allergies in Childhood (ISAAC) Phase Three: a global synthesis. Allergol Immunopathol (Madr). 2013;41:73-85.

2. Khazaei HA, Hashemi SR, Aghamohammadi A, Farhoudi A, Rezaei N. The study of type 1 allergy prevalence among people of south-east of Iran by skin prick test using common allergens. Iran J Allergy Asthma Immunol. 2003;2:165-168.

3. Kim BJ, Jung JA, Lee JS. Association between social economic status and atopic dermatitis in Korean adult: an analysis of the fifth Korean national health and nutritional examination survey (2010-2012). Allergy Asthma Respir Dis. 2015;3:128-133.

4. Wang DY. Risk factors of allergic rhinitis: genetic or environmental? Ther Clin Risk Manag. 2005;1:115-123.

5. A healthier children [Internet]. A better world. World without allergy. Toronto: SickKids Foundation. [Cited on 2014 Sep 5] Available from:https://www.sickkidsfoundation.com/artez/downloads/Allergy-Program-Summary.pdf Boye JI.

6. Food allergies in developing and emerging economies: need for comprehensive data on prevalence rates. Clin Transl Allergy. 2012;2:25.

7. Bousquet J, Bousquet PJ, Godard P, Daures JP. The public health implications of asthma. Bull World Health Organ. 2005;83:548-554.

8. Weinmann S, Kamtsiuris P, Henke KD, Wickman M, Jenner A, Wahn U. The costs of atopy and asth- ma in children: assessment of direct costs and their determinants in a birth cohort. Pediatr Allergy Immunol. 2003;14:18-26.

9. Samolinski B, Sybilski AJ, Raciborski F, Tomaszewska A, Samel-Kowalik P, Walkiewicz A, et al. Prevalence of rhinitis in Polish population according to the ECAP(Epidemiology of Allergic Disorders in Poland) study. Otolaryngol Pol. 2009;63:324-330.

10. Lobo F, Lobo B. Quality of Life in Asthmatic Outpatients. J Asthma. 2008;45:27-32.

11. Simpson CR, Newton J, Hippisley-Cox J, Sheikh A. Incidence and prevalence of multiple allergic disorders recorded in a coastal primary care database. J R Soc Med. 2008;101:558-563.

12. Hwang CY, Chen YJ, Lin MW, Chen TJ, Chu SY, Chen CC, et al. Prevalence of atopic dermatitis, allergic rhinitis and asthma in Taiwan: a national study 2000 to 2007. Acta Derm Venereol. 2010;90:589-594.

13. Enroth S, Dahlbom I, Hansson T, Johansson A, Gyllensten U. Prevalence and sensitization of atopic allergy and coeliac disease in the Northern Sweden Population Health Study. Int J Circumpolar Health. 2013;72.

14. Allergy questionnaire [Internet]. Burlington. [Cited 2014 Mar 9] Available from: http://www.burlingtonent. com/files/allergy-questionnaire.pdf

15. Kusunoki T, Morimoto T, Nishikomori R, Yasumi T, Heike T, Fujii T, et al. Changing prevalence and severity of childhood allergic diseases in Kyoto, Japan, from 1996 to 2006. Allergol Int. 2009; 58:543- 548.

16. Sakashita M, Hirota T, Harada M, Nakamichi R, Tsunoda T, Osawa Y, et al. Prevalence of allergic rhinitis and sensitization to common aeroallergens in a Japanese population. Int Arch Allergy Immunol. 2009;151:255-261. 17. Tham KW, Zuraimi MS, Koh D, Chew FT, Ooi PL. Associations between home dampness and presence of molds with asthma and allergic symptoms among young children in the tropics. Pediatr Allergy Immunol. 2007;18:418-424.

18. Dennis RJ, Caraballo L, García E, Rojas MX, Rondon MA, Perez A, et al. Prevalence of asthma and other allergic conditions in Colombia 2009-2010: a cross-sectional study. BMC Pulm Med. 2012;12:17.

19. Bousquet J, Khaltaev N, Cruz AA, Denburg J, Fokkens WJ, Togias A, et al. Allergic Rhinitis and its impact on Asthma (ARIA) 2008 update (in collaboration with the World Health Organization, GA(2)LEN and AllerGen). Allergy. 2008;63 Suppl 86:8-160.

20. Flokstra-de Blok BM, DunnGalvin A, Vlieg-Boerstra BJ, Oude Elberink JN, Duiverman EJ, Hourihane JO, et al. Development and validation of the self-ad- 
ministered Food Allergy Quality of Life Questionnaire for adolescents. J Allergy Clin Immunol. 2008;122:139144.

21. Soto MTS. Prevalence, severity and risk factors of asthma, rhinitis and eczema symptoms in school-aged children from Oropeza Province - Bolivia [dissertation]. Munich: Ludwig-Maximilians-Universitat; 2013.

22. Garcia E, Aristizabal G, Vasquez C, Rodriguez-Martinez CE, Sarmiento OL, Satizabal CL. Prevalence of and factors associated with current asthma symptoms in schoolchildren aged 6-7 and 13-14 yr old in Bogotá, Colombia. Pediatr Allergy Immunol. 2008;19:307-314.

23. Food allergy [Internet]. Balgowlah NSW, Australia: Australasian Society of Clinical Immunology and Allergy; 2015 [Cited 2014 Sep 10]. Available from:http:// www.allergy.org.au/images/pcc/ASCIA_PCC_Food_ Allergy_2015.pdf

24. Goossens NJ, Flokstra-de Blok BM, Vlieg-Boerstra BJ, Duiverman EJ, Weiss CC, Furlong TJ, et al. Online version of the food allergy quality of life questionnaire-adult form: validity, feasibility and cross-cultural comparison. Clin Exp Allergy. 2011;41:574-581.

25. Marklund B, Ahlstedt S, Nordstrom G. Food hypersensitivity and quality of life. Curr Opin Allergy Clin Immunol. 2007;7:279-287.

26. Ortolani C, Pastorello E. Food allergies and food intolerances. Best Pract Res Clin Gastroenterol. 2006;20:467483.

27. Nagel G, Weinmayr G, Kleiner A, Garcia-Marcos L, Strachan DP. Effect of diet on asthma and allergic sensitisation in the International Study on Allergies and Asthma in Childhood (ISAAC) Phase Two. Thorax. 2010;65:516-522.

28. Ellwood P, Asher MI, Garcia-Marcos L, Williams H, Keil U, Robertson C, et al. Do fast foods cause asthma, rhinoconjunctivitis and eczema? Global findings from the International Study of Asthma and Allergies in Childhood (ISAAC) phase three. Thorax. 2013;68:351360.

29. Palmer DJ, Metcalfe J, Makrides M, Gold MS, Quinn $\mathrm{P}$, West CE, et al. Early regular egg exposure in infants with eczema: A randomized controlled trial. J Allergy Clin Immunol. 2013;132:387-392.

30. Koplin JJ, Dharmage SC, Ponsonby AL, Tang ML, Lowe AJ, Gurrin LC, et al. Environmental and demographic risk factors for egg allergy in a population-based study of infants. Allergy. 2012;67:1415-1422.

31. Miyake Y, Tanaka K, Arakawa M. Sibling number and prevalence of allergic disorders in pregnant Japanese women: baseline data from the Kyushu Okinawa Maternal and Child Health Study. BMC Public Health. 2011;11:561.

32. Tanaka K, Miyake Y, Kiyohara C. Environmental factors and allergic disorders. Allergol Int. 2007;56:363396.

33. Willers SM, Brunekreef B, Oldenwening M, Smit HA, Kerkhof M, De Vries H, et al. Gas cooking, kitchen ventilation, and asthma, allergic symptoms and sensitization in young children - the PIAMA study. Allergy. 2006;61:563-568.

34. Miyake Y, Miyamoto S, Ohya Y, Sasaki S, Matsunaga I, Yoshida T, et al. Association of active and passive smoking with allergic disorders in pregnant Japanese women: baseline data from the Osaka Maternal and Child Health Study. Ann Allergy Asthma Immunol. 2005;94:644-651.

35. Lee CH, Chuang HY, Hong CH, Huang SK, Chang YC, Ko YC, et al. Lifetime exposure to cigarette smoking and the development of adult-onset atopic dermatitis. Br J Dermatol. 2011;164:483-489. 